\title{
Cadenas y redes migratorias: propuesta metodológica para el análisis diacrónico-temporal de los procesos migratorios
}

\author{
Claudia Pedone \\ Institut de l'Infancia i Món Urbà (CIIMU) \\ claudiapedone@yahoo.es
}

Recibido: 10.09 .2009

Aceptado: 24.02 .2010

Un abordaje desde la perspectiva teórico-metodológica del análisis de las cadenas y redes migratorias que trascienda el uso metafórico y retórico que, en algunas épocas, estigmatizó a esta perspectiva, exige idear herramientas metodológicas que permitan analizar en profundidad las relaciones de poder, la articulación y la dinámica de los vínculos de la población migrante que, en última instancia, se manifiesta en la configuración de las cadenas y redes migratorias. Este artículo presenta los resultados de una investigación que llevo a cabo en la última década con familias ecuatorianas que han protagonizado el flujo migratorio masivo y acelerado a partir de 1999 a España. Mediante un trabajo de campo etnográfico desde una perspectiva transnacional y transatlántica (origen/destino) y utilizando estrategias metodológicas cualitativas como la observación participante, la entrevista en profundidad, grupos de discusión y contactos periódicos con los y las líderes migrantes se han reconstruido cadenas y redes migratorias de familias ecuatorianas.

El material etnográfico producido en la última década, siguiendo los cambios y resignificaciones de algunos proyectos migratorios, permite abordar de qué manera se producen las decisiones individuales, qué elementos subjetivos intervienen y cómo afectan las condiciones estructurales en tales decisiones. El énfasis puesto en las diversas trayectorias socioespaciales ha permitido reconstruir el complejo entramado de los vínculos horizontales y verticales dentro de las redes migratorias: ayuda, cooperación, solidaridad, control, autoridad moral y económica, estrategias de dominación. La forma de estructuración que adquieren las redes en particular y el papel que juegan cada uno de los actores en su dinámica es significativo, puesto que algunas son articuladas verticalmente por diversos actores que detentan el poder, por ejemplo en cuanto al acceso al trabajo 
o a la vivienda, y otras horizontales como las establecidas por otros migrantes ya establecidos en la comunidad de llegada formada por algunos amigos, parientes y vecinos. Uno de los principales desafíos a nivel metodológico era buscar herramientas analíticas que nos condujeran a la identificación de las relaciones horizontales y verticales, su entrecruzamiento dentro de las mismas redes, y al reconocimiento de quienes eran los principales actores que le otorgaban uno u otro carácter.

La reconstrucción de la historia individual y familiar de un/a migrante, desde una perspectiva diacrónica, permite desentrañar las fases de un proceso que, en el marco de los procesos de globalización económica, adquiere connotaciones específicas y perpetúa otras heredadas de antiguas estructuras políticas y socioeconómicas. De aquí la relevancia de construir una metodología cualitativa que se ajuste al estudio de las migraciones internacionales, a partir del análisis de las redes y cadenas migratorias, y sus especificidades a la luz de la globalización como es el caso que abordamos en nuestra investigación.

La finalidad de este artículo es presentar una propuesta teórica-metodológica que demuestre el potencial del enfoque de análisis de las cadenas y redes migratorias para analizar las trayectorias socioespaciales de las familias migrantes en los flujos migratorios contemporáneos. En primer lugar, presento algunos antecedentes del estudios de redes migratorias en las ciencias sociales; en segundo lugar, defino conceptualmente qué entiendo por cadena y red migratoria en nuestro estudio; en tercer lugar, detallo las estrategias metodológicas que utilicé para la reconstrucción de las mismas y por último, presento un estudio de caso sobre una cadena y red migratoria procedente de la provincia de Loja (sur de Ecuador) en sus trayectorias hacia Europa y en la construcción y consolidación de sus procesos de transnacionalismo. El análisis se centra en la dinámica y la configuración de las cadenas y redes migratorias a partir de los vínculos familiares, de parentesco y vecindad y la diversidad de trayectorias migratorias atravesadas por las relaciones de género y generacionales ${ }^{1}$.

${ }^{1}$ Por una cuestión de espacio en este artículo me he detenido en el análisis de una cadena y red migratoria procedente del sur de Ecuador con la finalidad de mostrar las estrategias metodológicas utilizadas en nuestra investigación. Otros resultados empíricos que ilustran la metodología aquí desarrollada pueden consultarse en Pedone, C. (2006), Estrategias migratorias y poder. 'Tú siempre jalas a los tuyos. Quito: ABYA-YALA-PMCD-AECI, como por ejemplo La Diversificación de dos cadenas migratorias procedentes de Baños del Tungurahua, Ecuador (1993-2001) (Cap III. Pag. 136) y La Trayectoria socioespacial de una cadena migratoria procedente de Quito: mujeres como primeros eslabones migratorios (1992-2001) (Cap. V. Pag. 305). 


\section{ALGUNOS ANTECEDENTES DEL ENFOQUE DE CADENAS Y REDES MIGRATORIAS DESDE LAS CIENCIAS SOCIALES ${ }^{2}$}

La contribución sobre el enfoque de las redes sociales es muy vasta y revela una gran complejidad, no sólo por la cantidad de material a disposición, sino también porque la aproximación al estudio de la red revela una multiplicidad de marcos de referencia teórico-conceptuales, objetos de análisis, metodologías y técnicas empleadas ${ }^{3}$. Dentro de las ciencias sociales existen, principalmente, dos disciplinas vinculadas a dos escuelas particulares que han abordado el tema de las redes sociales desde perspectivas teórico-conceptuales y metodológicas divergentes. Se trata de la antropología británica con una perspectiva analítica situacional, procesual y diacrónica que en sus investigaciones reconstruyen la dinámica del tejido de relaciones interpersonales y analizan los mecanismos sociales que dan cuenta de las diferenciación de los comportamientos; y la sociología estadounidense con su abordaje estructuralista, morfológico y sincrónico, donde prevalecieron los estudios dentro de contexto nominalista sin tener en cuenta los procesos históricos y políticos, cayendo en una especie de «cuantofrenia» (Piselli 1995).

En relación al estudio de las redes migratorias, gran parte de la literatura se centra en la migración interna (Clyde Mitchell 1969; Lewis 1972; Lomnitz 1975; Gurak; Caces 1998). Otros estudios abordan las redes en los movimientos migratorios en relación a su articulación con el mercado de trabajo. En este sentido los trabajos de Mark Granovetter (1974) y de Margaret Grieco (1987) aparecen como clásicos. Desde tesis divergentes y contextos distintos, ambos analizan las oportunidades de acceso al empleo según los vínculos personales y familiares por los cuales se accede a la información.

Además, existe una abundante producción de estudios sociológicos sobre la inmigración de Puerto Rico, República Dominicana y México a Estados Unidos. No obstante, ellos se apoyan, fundamentalmente, en censos estadísticos y son muy pocos los que utilizan datos cualitativos, en el caso de hacerlo, este tipo de información se utiliza para hacer referencia a los contextos políticos en los que se articulan y funcionan las redes migratorias en cuestión. Por otra parte,

\footnotetext{
${ }^{2}$ Debido a que esta propuesta de análisis la he desarrollado en la última década, siguiendo numerosas trayectorias y proyectos migratorios de las familias ecuatorianas, algunos conceptos, definiciones y elecciones teórico-metodológicas tienen sus antecedentes en Pedone, 2002, 2004 y 2005, período en el que construí el enfoque teórico-metodológico para este estudio.

${ }_{3}^{3}$ Los primeros abordajes en estudios realizados a partir de las redes sociales en contextos ajenos a la migración son elocuentes. De hecho encontramos investigaciones que abarcan desde el análisis de los movimientos sociales pasando por el estudio de las redes informales -elemento decisivo en la vinculación de las personas necesitadas con las fuentes potenciales de asistencias-, hasta aquellos otros que se basan en la idea de las redes para predecir comportamientos sociales como la acción colectiva en simulaciones de pequeños grupos (Gurak; Caces 1998; Molina 2001).
} 
utilizar el enfoque de cadenas y redes de manera metafórica (Piselli 1995; Ramella 1995), ha conducido a repetir estereotipos que se expresan en afirmaciones tales como que las redes reducen los costos de la inmigración debido a que suministra información, vivienda y trabajo (Malgesini 1998). Si bien existe un amplio espectro de investigaciones que abordan el tema de los recursos económicos, sociales y culturales en la migración (Massey; Espinosa 1999), en numerosas ocasiones, estos estudios enfatizan en el aspecto positivo de pertenecer a una red. En este sentido, los migrantes potenciales se beneficiarían de los recursos sociales emanados exclusivamente de los vínculos horizontales - normas de reciprocidad, lazos de solidaridad y obligaciones devenidas de la pertenencia a una comunidad específica asociadas con el parentesco, los lazos de amistad y de vecindad - para bajar los costos y los riesgos de los movimientos internacionales y acceder a los beneficios del acceso al empleo en los lugares de destino. Estos estudios parten de la idea que la acumulación de los recursos sociales incentiva el flujo migratorio, principalmente, cuando se trata de la entrada «clandestina» (Massey; Espinosa 1999), aunque, en general, no hacen referencia a la manera en que estas relaciones se verticalizan y, según los casos, a la forma en que este bagaje de información y contactos se convierten en un valor económico en manos de unos pocos: aquellos que poseen el poder dentro de las redes.

A partir de la década de 1980, la historia social, influenciada por las nuevas aproximaciones antropológicas y sociológicas, ha restaurado el papel de los individuos en la construcción de los vínculos sociales. Así, se producen algunos desplazamientos fundamentales como el de estructura de redes, desde los sistemas de posiciones hasta las situaciones vividas, desde las normas colectivas a las estrategias singulares.

Los estudios inscritos dentro de la microhistoria surgieron de la crisis del paradigma positivista en las ciencias sociales, en las décadas de 1970 y 1980 . En definitiva, se retorna al actor social y se recupera la función explicativa desde los protagonistas que habían vivido el proceso en el cual se encontraban involucrados y que interesaba explicar e interpretar; este hecho se vincula con el estudio de las relaciones sociales y las estrategias llevadas a cabo por los propios individuos y los grupos sociales (Devoto 1991).

Desde la perspectiva de la microhistoria, a principios de la década de 1950, el concepto de «cadena migratoria» se constituye en uno de los esquemas teóricos predominantes para el estudio de las migraciones internacionales. Los estudios pioneros sobre este enfoque se gestan en ámbitos académicos australianos (Lochore 1951), continuaron el trabajo de Borrie (1954) que abordó la migración italiana y alemana a Australia y el de Price (1963) con el análisis de los desplazamientos de los europeos del sur hacia ese mismo país.

Será en la década de 1980 cuando los microhistoriadores se tornarán en especialistas que dedicarán una importante parte de su producción al análisis de las cadenas migratorias. Especialistas italianos, estadounidenses, canadienses y argentinos aplicarán esta postura teórico-metodológica al análisis a la inmigración 
italiana y española en Argentina, Estados Unidos y Canadá de fines del siglo XIX y principios del siglo $\mathrm{XX}^{4}$.

En definitiva, el concepto de cadena migratoria y de red migratoria ha sido utilizado en las últimas décadas con distintos significados por los cientistas sociales ${ }^{5}$. En la búsqueda de conceptos y metodología adecuada para construir una perspectiva que permitiera analizar la articulación, dinámica y configuración de los proyectos migratorios en los desplazamientos internacionales contemporáneos, creímos necesario acudir a las herramientas teórico-metodológicas elaboradas por la antropología social y la microhistoria.

\section{LAS CADENAS Y REDES MIGRATORIAS EN LOS DESPLAZAMIENTOS INTERNACIONALES CONTEMPORÁNEOS: UNA PROPUESTA DE ANÁLISIS}

Mi investigación tiene sus inicios a fines de la década de 1990. En esa época, en España, el fenómeno de la inmigración extracomunitaria y su sobredimensionamiento político y mediático, coincide con la posición del Estado de considerarlo como «un problema» y como «una invasión», y las referencias a redes migratorias aludían a redes de cooperación y solidaridad o se asociaban a redes ilegales de tráfico de personas.

Una de las condiciones más notables implicadas en la consolidación de los estudios sobre la inmigración en España es el hecho de que este fenómeno es una cuestión de Estado lo cual intentaría separar la dimensión política de la inmigración y su gestión. Algunos autores sostenían que la creciente demanda de este «poderoso cliente» determinó, en numerosas ocasiones, la forma en que los resultados fueron presentados y ha sido decisiva en la manera en que en este campo de estudios se conformó, evolucionó y, actualmente, se está reconfigurando (Bustos Cortés 1993; Ramírez Goicoechea 1997; García Borrego 2000; Solana, Morén; de Miguel; Pascual, 2002).

Debido a su estrecha sujeción a la visión del Estado, una de las principales características que presentaban estos estudios es la de acotarse al ámbito terri-

${ }^{4}$ Es oportuno aquí destacar el surgimiento en 1985 de la Revista Estudios Migratorios Latinoamericanos, dirigida por el historiador argentino Fernando Devoto que se constituyó en un ámbito de análisis y de debate que proporcionan numerosos trabajos de investigación desde la microhistoria no sólo italiana y argentina, sino también se ponen en discusión las propuestas de los investigadores australianos y norteamericanos mencionados. Este grupo de investigadores en torno a esta revista y a algunos libros, editados en forma conjunta, conjugan las perspectivas de ambas orillas del Atlántico, puntos de vistas que enriquecen nuestra mirada transatlántica, postura elegida para abordar nuestra investigación.

${ }^{5}$ Para un estado de la cuestión sobre los estudios de redes migratorias en las ciencias sociales consultar: Pedone, C. (2004): «'Tú siempre jalas a los tuyos'. Cadenas y redes migratorias de las familias ecuatorianas hacia España», Barcelona, Universitat Autònoma de Barcelona. Tesis doctoral (inédita) Cap.III. 
torial estatal, elección que entra en contradicción directa con el carácter internacional y transnacional de los flujos migratorios contemporáneos. En este sentido, el recorte del fenómeno a un territorio cerrado sólo puede sostenerse desde determinadas estrategias - control o utilización de los inmigrantes - o concepciones ideológicas que consideran al Estado-nación como al ámbito «natural» desde el que se debe analizar el fenómeno, lo que se ha denominado como «nacionalismo metodológico» (Colectivo IOE 1999; Wimmer; Glick Schiller 2002; Suárez Navas 2008).

Por ello, era necesario construir una propuesta teórico-metodológica que considerara a los y las inmigrantes como sujetos capaces de crear y llevar adelante estrategias migratorias para moverse en contextos micro y macroestructurales en la fase actual del capitalismo.

Desde la microhistoria los aportes han sido diversos, permitiendo una observación que privilegia el comportamiento de los individuos y del grupo en relaciones atravesadas tanto por el conflicto como por la cooperación (Bragoni 1999). Ya en la década de 1960, el concepto pasó a ser un eje teórico-metodológico central en las investigaciones realizadas en Estados Unidos; el estudio que constituyó la punta de lanza fue el de Mac Donald y Mac Donald (1964) sobre Chain Migration, Ethnic Neighborhood Formation and Social Networks. La definición sobre cadena migratoria que proponen estos autores y el análisis que realizan a partir de la experiencia de la migración italiana en Estados Unidos y en Australia son utilizados durante la década de 1960 y la siguiente por numerosos investigadores que continuaron con este abordaje teórico-metodológico ${ }^{6}$. Así los Mac Donald, formulan una definición de cadena migratoria que con los años se convertiría en clásica, «la cadena migratoria puede ser definida como el movimiento a través del cual los presuntos emigrantes se enteran de las oportunidades, son provistos de transporte y obtienen su instalación inicial y empleo, por medio de relaciones sociales primarias con emigrantes anteriores» ${ }^{7}$.

Este concepto, en una primera instancia, apuntaba a diferenciar una de las modalidades del proceso migratorio frente a los desplazamientos organizados a partir de sistema de reclutamiento y asistencia a los inmigrantes. El abordaje analítico de la cadena migratoria permitía explicar quién debía emigrar, dónde, cómo y cuáles serían los patrones de asentamiento y ocupacionales de los emigrantes (Baily 1988; Devoto 1988). En la década de 1980, en Canadá Robert Harney produjo junto con sus discípulos una serie de investigaciones que introdujeron matizaciones y algunos conceptos precursores que contribuyeron a aclarar más el concepto de cadena migratoria y a limitarlo. Desde el punto de vista de Robert Harney, la interpretación de la emigración como un proceso en cadena que pone en marcha mecanismos de solidaridad entre los migrantes estaría contrapuesta a las relaciones de explotación presentes en aquello que Har-

\footnotetext{
${ }^{6}$ Una detallada enumeración de los estudios en América del Norte que toman el planteo de los Mac Donald puede encontrarse en Baily, 1988: 133, 134.

7 Mac Donald, J. S., Mac, Donald, L. D., 1964: 82.
} 
ney denominaba «comercio de la emigración». Debido a la dificultad que existe en establecer dónde termina la solidaridad y empieza la explotación, Harney considera que el problema se puede dilucidar abordando las relaciones de poder desiguales entre distintos eslabones de la cadena, o mediante la horizontalidad y la verticalidad en las relaciones sociales.

Es también entre los historiadores que se ha dado la discusión sobre la diferenciación entre cadena migratoria y redes. En este punto coinciden Ramella (1995) y Míguez (1995) cuando reconocen la evidencia sobre la construcción de una nueva trama de relaciones vinculada con la inserción de inmigrantes en la sociedad de llegada. Este hecho genera una «red de arribo» no basada necesariamente en solidaridades migratorias establecidas en el comienzo del proceso migratorio en torno a las relaciones familiares o de parentesco. Este es un elemento clave de diferenciación para analizar la complejidad ya de las redes, traspasando la cadena migratoria, en principio constituida alrededor de la familia nuclear y extendida.

Sobre la base de este debate, en la investigación sobre el flujo migratorio ecuatoriano hacia España en la última década, propuse diferenciar conceptualmente cadena migratoria de red migratoria con la finalidad de alcanzar una mayor comprensión analítica.

Así, entonces, el concepto de cadena migratoria se refiere a la transferencia de información y apoyos materiales que familiares, amigos o paisanos ofrecen a los potenciales migrantes para decidir, o eventualmente, concretar su viaje. Las cadenas facilitan el proceso de salida y llegada, pueden financiar en parte el viaje, gestionar documentación o empleo y conseguir vivienda (McDonald 1964; Malgesini; Giménez 1997). También en ellas se produce un intercambio de información sobre los aspectos económicos, sociales y políticos de la sociedad de llegada. En nuestro estudio restringimos las cadenas migratorias al grupo doméstico, el cual, a su vez, traspasa los límites de la unidad residencial. Las cadenas forman parte de una estructura mayor: las redes migratorias. Las redes migratorias son estructuras sociales mayores que trascienden los límites geográficos y tienen un carácter eminentemente transnacional, e involucran a todas aquellas personas e instituciones que están vinculadas al hecho migratorio: políticas de estado (origen y destino), migrantes, empleadores y empleadoras, ONGs, personal de servicios sociales (preferentemente educación y salud), instituciones religiosas, asociaciones de migrantes. Las redes difieren en función según se traten de redes internas o internacionales. Por ello, el contexto político internacional genera una especificidad en el tipo, la dinámica y la diversificación de la red; de este modo, los vínculos mantenidos entre diferentes actores tanto en la sociedad de origen como en la de llegada, conformarían campos sociales trasnacionales (Glick Schiller 1995; Suárez Navas 2008).

Analizar los procesos migratorios desde la perspectiva transnacional supone reconocer la existencia de relaciones familiares, económicas, políticas, institucionales, culturales, religiosas que atraviesan fronteras, vinculan los contextos de origen y destino y construyen campos sociales transnacionales que trascienden 
los límites del Estado-Nación. Peggy Levitt y Nina Glick Schiller (2004) definen los campos sociales transnacionales como un conjunto múltiples redes de relaciones sociales transfronterizas, a través de las cuales se intercambian, organizan y transforman ideas, prácticas, recursos donde sujetos que no migran mantienen relaciones con quienes sí lo hacen. Así incluso las vidas de personas que sólo se desplazan excepcionalmente o nunca, como los familiares de los migrantes que permanecen en el lugar de origen, se ven inmersas e influenciadas por prácticas de carácter transnacional.

Desde el enfoque propuesto intentamos reconstruir las redes sociales utilizadas por los y las migrantes, en unos casos para salir del país de origen y, en otros, para insertarse en el lugar de llegada y acceder a la vivienda, al mercado de trabajo y para considerar la posibilidad de migrar a otros destinos. Para ello, un elemento de vital importancia para la dinámica y consolidación de las redes es la calidad, la cantidad y los modos en que circula la información. La información no es la misma para todos los vecinos o coterráneos del pueblo, ni necesariamente se trasmite de vecino a vecino, porque los canales mediante los cuales aquella circula son las relaciones sociales fuertes que prescinden de la distancia y, por lo tanto, de la frecuencia de los contactos (Ramella 1995).

Un aspecto significativo en el estudio de las redes, es el que considera la fuerza del vínculo entre los individuos y su la familia dentro del mercado de trabajo. En este sentido, los estudios de Mark Granovetter (1974) y Margaret Grieco (1987) sobre la circulación de la información entre las redes de parentesco y amistad acerca de las posibilidades de empleo generaron un fructífero debate. Mientras Granovetter definía los vínculos como «fuertes» y «débiles» sobre la base de la frecuencia del contacto, Grieco sostenía que la fuerza del vínculo no se puede basar en la frecuencia del contacto físico. En efecto, como es particularmente evidente en el caso de la cadena migratoria, parientes que viven en áreas geográficas distantes y con quienes los contactos a veces son esporádicos, constituyen todavía, un vínculo fuerte útil para facilitar la movilidad ocupacional. Además, la autora incorpora a su análisis la relevancia de la obligación recíproca que caracteriza a este tipo de relaciones. A pesar de las divergencias surgidas entre ambos trabajos, ambos autores realizaron un aporte válido al enfoque interpretativo, demostrando la complejidad que presenta el mercado de trabajo y el peso que tiene la variable social transversal a todo el desarrollo del proceso económico.

Es en este punto donde la estructura que adquieren las redes, en particular, y el papel que juegan cada uno de los actores en su dinámica es significativo, puesto que algunas son articuladas verticalmente (definidas por la desigualdad en las relaciones y la jerarquía que ocupan los y las migrantes dentro de la cadena y/o la red) por diversos actores que detentan el poder, por ejemplo, en cuanto al acceso al trabajo o la vivienda, y otras horizontales (relaciones basada en la reciprocidad, lealtad, solidaridad y cooperación) como las establecidas por otros y otras migrantes ya establecidos en la comunidad de llegada formada por amigos y parientes. 
Desde los inicios de la conformación de las cadenas y redes migratorias, se configuran una serie de relaciones de poder ${ }^{8}$ que intervienen en la selectividad de los futuros migrantes (Gurak; Caces 1998). En este sentido, es necesario tener en cuenta los diferentes tipos de roles que los y las migrantes juegan para que las redes presenten vínculos de verticalidad y horizontalidad.

Esta configuración del poder otorga sentido a ciertas trayectorias socioespaciales donde diferentes actores poseen el poder económico y simbólico que, en algunas ocasiones, facilitan el primer aterrizaje, el acceso a la vivienda y al trabajo, y en otras ocasiones, pueden obstaculizar los movimientos de otros migrantes.

La multidimensionalidad de los procesos migratorios internacionales conlleva a una complejización de vínculos que nos conduce a incorporar diferentes elementos de análisis para lograr una mayor comprensión. Por ello, el estudio de la articulación y dinámica entre las cadenas y redes migratorias requiere de algunas matizaciones que pueden abordarse desde la diversificación de las cadenas. Las cadenas tienen lugares de destino claves específicos, la intensidad del atractivo que ejerce algunos de estos lugares puede sufrir un reflujo y, así, las trayectorias socioespaciales pueden cambiar de destino. Además, simultáneamente con el flujo migratorio principal que proviene de un lugar determinado, existe siempre una dispersión general, por diversos motivos, hacia otros lugares de la sociedad de destino. Los flujos migratorios, para llegar a estos lugares, se encauzan impulsados por los vínculos de parentesco, de vecindad, por relaciones con personas autóctonas o por la combinación de todos estos vínculos (Sturino 1988).

Desde el momento de partida, la elección de quién migra, los motivos de la migración, la permanencia y/o el retorno ocurre articulando una red de relaciones que envuelven género, parentesco y generación (De Oliveira Assis; Siqueira 2009).

Algunos estudios parten de la idea de que la decisión de migrar no siempre obedece a decisiones individuales sino que forma parte del proyecto migratorio la familia. Por ello, es necesario analizar qué representa simbólicamente la familia, en el sentido que constituye un espacio en el cual se dan prácticas de socialización como las de reproducción y las de convivencia entre género y generaciones; a la vez que es un espacio de ejercicio de autoridad (Horkheimer 1980, 1986; García Canclini 1990; Salles; Smith 1987; Salles 1991).

En el contexto migratorio transnacional, la familia es la iniciadora de la cadena migratoria. Ella estimula y facilita el acceso al trabajo y en su centro se desarrollan una serie de estrategias para la sobrevivencia y la asistencia dentro del proyecto migratorio. El hecho de que la decisión de migrar sea de carácter familiar involucra fundamentalmente la posición de la mujer en el proceso. Justa-

${ }^{8}$ Seguimos aquí la conceptualización de poder de Weber (1994) para quien este término significa «la probabilidad de imponer la propia voluntad, dentro de una relación social, aún contra toda resistencia y cualquiera que sea el fundamento de esa probabilidad». 
mente la visibilización de las mujeres y los niños dentro de la familia y como parte decisional en el juego de las relaciones de poder ha permitido centrar el análisis de la familia como un lugar de conflicto y negociación (Morokvasic 1984; Pessar 1984; Gregorio Gil 1998).

A partir de la década de 1990, nuevos estudios basados en las migraciones femeninas han aportado una serie de elementos de análisis que han enriquecido las perspectivas para abordar la problemática de la migración internacional, el mercado de trabajo y sus vinculaciones mediante cadenas familiares. En este sentido, es imprescindible tener en cuenta la transferencia transnacional del trabajo reproductivo que necesita ser contextualizado y analizado más allá de las específicas configuraciones de cambios y permanencias entre las relaciones de género sino que se debe involucrar diversos niveles: los Estados, la familia y la nueva estratificación mundial del mercado de trabajo (Truong 1996). Fueron los análisis sobre las redes migratorias desde la perspectiva transnacional, y atentos a las relaciones de género, los que han hecho emerger las dinámicas familiares como terrenos de investigación y producción de conocimientos sobre los movimientos migratorios (Mahler, Pessar 2006).

Nuestra propuesta de investigación contempla las relaciones de género como un eje transversal de análisis dentro del proyecto migratorio internacional, con este enfoque pretendemos superar los sesgos que denotan los trabajos que no toman en cuenta que la mayoría de las sociedades están estructuradas por género y que este hecho suele conllevar una serie de desigualdades en el acceso a los recursos de todo tipo: políticos, económicos y sociales (Gregorio Gil, 1998).

Existe una abundante literatura sobre críticas a las aproximaciones teóricas que sustentan el enfoque de las cadenas y redes migratorias ${ }^{9}$, no obstante, el debate metodológico sobre qué estrategias utilizar a la hora de reconstruir y analizar la dinámica y configuración de las cadenas y redes migratorias han permanecido en un segundo plano. En el siguiente apartado, me centraré en la construcción del proceso de investigación que llevo a cabo desde hace una década para analizar la dinámica, articulación y configuración de las cadenas y redes migratorias ecuatorianas hacia España.

\section{DISEÑO Y CONSTRUCCIÓN DE UN PROCESO DE INVESTIGACIÓN}

Una de mis principales preocupaciones teórica-metodológica durante el proceso de investigación era trascender el uso metafórico y retórico que, en al-

${ }^{9}$ El último número de la Revista Interdisciplinar da Mobilidade Humana del Centro Scalabriniano de Estudos Migratórios, N. ${ }^{\circ} 32$ (2009), dedica un monográfico al debate actual de las investigaciones de Redes Migratorias. Para una crítica, principalmente a los estudios sobre redes migratorias derivados de sociología estadounidense consultar Fanzito, Dimitri (2009): «The role of social Networks in human migration».

EMPIRIA. Revista de Metodología de Ciencias Sociales. N. . 19, enero-junio, 2010, pp. 101-132. ISSN: $1139-5737$ 
gunas épocas, estigmatizó a la perspectiva de análisis de las cadenas y redes migratorias. En este sentido, un objetivo metodológico primordial era idear herramientas que me permitieran analizar en profundidad la problemática de la diversificación de las cadenas mediante el análisis de las relaciones de poder y la articulación y dinámica en los vínculos que, en última instancia, manifestarían la configuración de las cadenas y redes migratorias.

La relación entre el estudio de las redes migratorias y los relatos biográficos nos demuestra la intervención de todos estos elementos y permite el examen de las peculiaridades más comunes; importa indagar los efectos del proceso, los cambios que afectan de manera global a la vida de los individuos, tanto en lo que atañe a su vida cotidiana como a sus referentes simbólicos. Así, en las entrevistas surgen las percepciones que el inmigrante tiene de la sociedad de llegada y de otros colectivos de inmigrantes.

La biografía tiene, respecto de otros métodos, la ventaja de recoger la experiencia de las personas, tal como ellas la procesan e interpretan. Esa revelación de hechos e interpretaciones explícita e implícitamente está filtrada por las creencias, actitudes y valores del y la protagonista (Golby 1997).

Además, en los relatos de vida son tan importantes los hechos que aparecen cómo la forma de narrarlos, de ahí que, las narrativas son diferentes según el género y las generaciones. Una mirada atenta a los relatos de vida nos descubre de qué manera se producen las decisiones individuales, qué elementos subjetivos intervienen y cómo afectan las condiciones estructurales en tales decisiones, en su orientación. Si dentro de los relatos de vida hacemos hincapié en las diversas trayectorias socioespaciales, paulatinamente, es posible reconstruir el complejo entramado de los vínculos horizontales y verticales dentro de las redes migratorias: ayuda, control, cooperación, solidaridad, control moral, autoridad moral y económica, estrategias de dominación.

Nuestra propuesta metodológica supone un análisis diacrónico-temporal, centrado en el análisis de los vínculos «fuertes» y «débiles» y en las relaciones verticales y horizontales que articulan la dinámica de las cadenas y redes migratorias, por medio de relatos biográficos, entrevistas en profundidad, observación participante, contactos periódicos con los y las migrantes que detentan el poder en las cadenas y/o redes y trabajo de campo transnacional (origen y destino).

La forma de estructuración que adquieren las redes en particular y el papel que juegan cada uno de los actores en su dinámica es significativo, puesto que algunas son articuladas verticalmente por diversos actores que detentan el poder, por ejemplo en cuanto al acceso al trabajo o la vivienda, y otras horizontales como las establecidas por otros migrantes ya establecidos en la comunidad de llegada formada por amigos y parientes con proyectos migratorios más consolidados. En este sentido, uno de los principales desafíos a nivel metodológico era buscar herramientas analíticas que nos condujeran a la identificación de las relaciones horizontales y verticales, su entrecruzamiento, y al reconocimiento de quienes eran los principales actores que le otorgaban uno u otro carácter. 


\section{Un trabajo de campo transnacional: los y las migrantes como generadoras de conocimiento ${ }^{10}$}

Como investigadores e investigadoras, somos responsables de un gran número de desplazamientos, del campo a la academia y de ésta al campo, entre otros, raramente mencionados en nuestros trabajos o en la comunicación de los resultados. Desde esta perspectiva el «campo» se resignifica en cada uno de los desplazamientos. De ser un lugar o una población más bien localizado pasa a ser definido en términos de relaciones de poder en diferentes ámbitos, que lo cortan transversalmente en el tiempo y en el espacio. Por ello, el «campo» no se restringe a la actividad de traslado a un determinado sitio para realizar nuestra investigación, sino que está presente en todo el proceso y de múltiples maneras.

Abordar el análisis de las relaciones de poder dentro de las cadenas y redes migratorias, suponía, también, analizar las relaciones de poder que se generan entre el o la investigadora y la población con la cual se trabaja. Para ello, es necesario realizar un paso cualitativo a nivel metodológico del sujeto cognoscente al sujeto conocido, entendida como una relación de igualdad y cooperativa entre sujetos que producen conocimientos y el o la investigadora. Desde esta perspectiva, el principio de igualdad esencial presupuesto en el proceso de conocimiento le otorga, entonces, al sujeto conocido un papel privilegiado en la definición de sus aspiraciones, de sus deseos, de sus motivaciones, de sus fines, de sus propósitos, de sus valores y ese papel no puede ser asumido por el investigador o la investigadora. La validez del conocimiento para el enfoque de la epistemología del sujeto conocido será más sólida, cuando menos se tergiversan las acciones, los sentimientos, los significados, los valores, las interpretaciones, las evaluaciones, en definitiva, la identidad de ese sujeto conocido (Vasilachis de Gialdino 2000).

Ahora bien, partir de la postura de que es necesaria la construcción de una relación de igualdad entre sujeto conocido y sujeto cognoscente supone, además, reflexionar sobre las políticas de trabajo de campo, los desplazamientos, las prácticas, sociales, políticas y académicas del o la investigadora, en definitiva, cuáles son sus espacios intermediarios ${ }^{11} \mathrm{y}$ de qué manera se alcanza el voto de confianza que sienta las bases de la pretendida relación cooperativa, donde a su vez, el sujeto conocido evalúe los resultados del sujeto cognoscente.

${ }^{10}$ Expreso mi profundo agradecimiento a las familias migrantes de El Pindal, Loja que desde hace una década se involucran en mi investigación dedicando su tiempo y conocimiento para generar los resultados que aquí se presentan y me han permitido entrar en sus casas y conocer sus «arreglos familiares» en sus vitadas cotidianas transnacionales, en especial a Lorgia Rogel y Fabián Cabrera.

${ }^{11}$ El espacio intermediario entendido como varios espacios (el campo, la universidad, los espacios de la vida cotidiana, las prácticas sociales y políticas) en los cuales el o la investigadora se encuentra de forma simultánea. En todos ellos existen particulares relaciones de poder. Ello implica diferentes desplazamientos estratégicos, retóricos y empíricos que emergen de nuestro conocimiento en un compromiso político que trabaja contra las estructuras de dominación (Katz, 1992, 1994, Pedone, 2000). 
En este sentido, la perspectiva metodológica construida para analizar la articulación y la dinámica de las cadenas y redes migratorias de las familias ecuatorianas a España fue elaborada a partir de las prácticas de la investigación biográfica y de la reflexión sobre la relación existente entre las personas con las cuales trabajé y mi condición de investigadora, inmigrante latinoamericana y la vivencia propia de los procesos de transnacionalismo como migrante e investigadora $^{12}$.

El uso de esta metodología me permitió aproximarme a los vínculos del parentesco, a las alianzas y a las relaciones personales. En una primera etapa, realicé 86 entrevistas en profundidad, en Totana 26 entrevistas, 15 a varones y 11 a mujeres; en Barcelona: 23 entrevistas, 15 a mujeres y 8 a varones; en Madrid: 27 entrevistas, 15 a varones y 12 a mujeres.

\section{Un muestreo teórico e intencional}

Para el desarrollo de la muestra definitiva elegimos el muestreo teórico que es aquel que permite encontrar aquellas categorías de personas o sucesos que se desea explorar con mayor profundidad. Este nos ayuda a determinar qué grupos analizar, dónde y cuánto, encontrarlos y también precisar qué datos solicitarles.

Este muestreo se orienta a la selección de aquellas unidades y dimensiones que le garanticen la mejor calidad y riqueza de información por lo que pueden incorporarse unidades de muestreo no previstas inicialmente y puede interrumpirse la selección de más unidades cuando el/la investigadora considere que ha llegado al punto de saturación. Esta saturación teórica se alcanza cuando el/la investigador/a que recoge y, al mismo tiempo, analiza la información entiende que los nuevos datos son repetitivos y ya no aportan información novedosa (Ruiz Olabuénaga, 1999).

La técnica de la «bola de nieve» sólo fue utilizada en el trabajo de campo exploratorio en Totana en setiembre de 1999, en la Rotonda de «La Turra» donde se recluta a los/as trabajadores/as para la actividad agrícola. Así, establecimos los primeros contactos para preparar la «entrada al campo». Los primeros datos nos revelaron que las mujeres y los varones ecuatorianos procedían, en su mayoría, de las mismas localidades de origen y que estaban vinculados por relaciones de parentesco, amistad y/o vecindad.

La primera etapa de trabajo de campo en Totana comienza en diciembre de 1999, donde testeamos el primer guión de entrevista propuesto. Allí me dirigí a

${ }^{12}$ Para mayor información sobre esta temática consultar, Pedone, C. (2000): «El trabajo de campo y los métodos cualitativos. Necesidad de nuevas reflexiones desde las geografías latinoamericanas». Scripta Nova. Revista Electrónica de Geografía y Ciencias Sociales, 57 (http://www.ub.es/geocrit/sn-57.htm); Pedone, C. (2004): «'Tú siempre jalas a los tuyos'. Cadenas y redes migratorias de las familias ecuatorianas hacia España», Barcelona, Universitat Autònoma de Barcelona. Tesis doctoral (inédita) Cap. IV.

EMPIRIA. Revista de Metodología de Ciencias Sociales. N. . 19, enero-junio, 2010, pp. 101-132. ISSN: 1139-5737 
las primeras personas contactadas previamente para que ellas nos guiaran a través de sus relaciones sociales.

Esta búsqueda intencionada de las personas migrantes en las tres áreas de estudio, se orientaba a cumplir con unos de nuestros principales objetivos en este estudio: encontrar y entender quiénes detentaban el poder dentro de las cadenas y redes migratorias ecuatorianas en Totana (Murcia), Barcelona y Madrid. Optar por este criterio metodológico nos posibilitó entrar en el complejo mundo donde las cadenas migratorias se diversifican y, al mismo tiempo, donde se articulan las diferentes dinámicas de las redes migratorias.

Por ello, acceder desde una cadena y red migratoria constituida en Barcelona a quienes articulaban las cadenas y redes migratorias en Madrid, todos/as ellos/as procedentes de Baños del Tungurahua, fue un ámbito socioeconómico privilegiado para reconstruir y analizar las relaciones de parentesco, vecindad y amistad, como así también, el entrecruzamiento de relaciones horizontales y verticales que determinan la dinámica de los vínculos sociales entre los/as migrantes involucradas en la construcción de un espacio social transnacional que llevaban a cabo desde inicios de la década de 1990. Otros miembros de cadenas migratorias procedentes de Quito y de Guayaquil proporcionaron igualmente los contactos para acceder la trama de otras redes migratorias que los vinculaba con Madrid.

Una vez concluidas las entrevistas en profundidad en las tres áreas de estudio propuestas en España: Totana (Murcia), Barcelona y Madrid, analizados los datos recogidos y, en vistas a esta flexibilidad en el muestreo, continuar con el trabajo de campo en los lugares de origen era una tarea imprescindible. De este modo, incorporamos a nuestras áreas de estudio algunos lugares de Ecuador. En efecto, entre setiembre y octubre del año 2001, trabajamos en Quito, Santo Domingo de los Colorados, Baños del Tungurahua, Cuenca, Loja y El Pindal.

En síntesis, el trabajo de campo se desarrolló en diversas etapas entre 1999 y 2002, además de las entrevistas en profundidad mencionadas realicé entrevistas a diversos actores que conformaban las redes estudiadas tanto en origen como en destino, mantuve y mantengo contactos periódicos con los y las líderes de las cadenas y redes, y por último, organicé grupos de discusión con abuelas y docentes en origen (Pedone 2004, 2006a).

\section{Trabajo de campo en el Ecuador: consolidar mi perspectiva transatlántica y transnacional}

Las investigaciones que estudian los grupos domésticos dentro de la migración internacional con una perspectiva etnográfica transnacional eran escasas a principios del año 2000. Generalmente, se analizaba el fenómeno en los lugares de llegada y se recogía información con los miembros más cercanos de la familia, especialmente, sino hay un número significativo de los miembros de un grupo doméstico específico en los lugares de destino. Adherir a la perspectiva 
transnacional sin realizar trabajo de campo en origen hace que el trabajo de investigación carezca de bases consistentes para el análisis de la relación entre la migración y los cambios que provoca en toda la estructura familiar tanto en el lugar de origen como en el de llegada.

Por ello, si el objetivo es estudiar la extensión y la configuración de las interrelaciones entre migración y el proceso de construcción familiar, es necesario obtener información no sólo de los migrantes, sino además, de los familiares que permanecen en el lugar de origen. Así se obtiene una referencia apropiada de la real constitución del grupo doméstico. En este sentido, me propuse reconstruir las relaciones familiares, sociales, económicas, financieras y políticas que generaban y consolidaban campos sociales transnacionales que enlazaban los lugares de origen y los lugares de llegada.

En setiembre del año 2001 llegué a Quito con una hoja de ruta organizada conjuntamente con los líderes de las cadenas y redes migratorias entrevistadas en España.

A nivel contextual, me interesaba observar las consecuencias que a escala nacional y regional traía este último flujo migratorio a España, para ello, me entrevisté con los grupos de investigación ecuatorianos que en ese tiempo comenzaban con proyectos de investigación sobre la problemática de la migración a España y con organizaciones religiosas como la iglesia católica. Las entrevistas con los representantes católicos me permitieron trabajar sobre uno de los presupuestos de mi investigación: el papel activo de la iglesia católica dentro de las redes migratorias tanto en origen como en destino y de qué manera intervenían en las trayectorias socioespaciales de los y las migrantes. Además, realicé una recorrida por la prensa ecuatoriana con el objetivo de poder comparar los discursos que desde el gobierno se emitían tanto en el lugar de origen como en el de destino.

Con respecto a los grupos domésticos era imprescindible comprender cómo se habían articulado las relaciones de género y generacionales entre sus miembros a la luz de estos nuevos campos sociales transnacionales y de qué modo se renegociaban los roles de maternidad, paternidad, la conducta de los hijos e hijas, la inversión de las remesas y la consolidación de los diversos proyectos migratorios identificados en destino. En cuanto a las relaciones de poder, nuestra observación participante en localidades pequeñas como Baños del Tungurahua, El Pindal se orientaba a identificar las prácticas sociales, económicas y financieras de los y las líderes.

Una buena parte de las personas procedentes de Baños del Tungurahua eran profesionales de la educación. Así, una cadena migratoria estaba compuesta exclusivamente en el lugar de origen por mujeres que se hacían cargo del proyecto migratorio en origen, ello implicaba por ejemplo la crianza de los niños y niñas mientras que las mujeres migrantes situadas en España y Estados Unidos enviaban remesas para diversos emprendimientos. Todas ellas estaban vinculadas con el sector de la educación y fueron quienes me propusieron la reunión con los maestros de la escuela porque, en su opinión, el impacto de la migración estaba causando graves daños afectivos en niños/as y adolescentes. 
Los contactos con las instituciones que trabajaban en Cuenca con familiares de emigrantes fueron proporcionados por los miembros de una cadena migratoria que vinculaba Totana con Cuenca. Juan arribó a Totana en el momento de llegadas masivas de ecuatorianos en 1998 y se incorporó rápidamente a la lucha por «los papeles» y a las actividades de la Asociación Murcia Acoge. Mantuve con él sucesivas entrevistas en mis periódicos viajes a Totana. Juan se contactó con su esposa para que me recibiera en la ciudad de Cuenca; las relaciones de Natalia fueron vitales para interactuar con las organizaciones y personas que estaban trabajando con el tema de la emigración a Estados Unidos y a España desde las provincias del Azuay y de Cañar. Además, sus agudos análisis referidos a las relaciones de poder dentro de las redes migratorias en origen fueron una importante contribución para el estudio.

En cuanto a la «entrada al campo» en Loja y El Pindal, dos cadenas migratorias residentes en Barcelona me posibilitaron el contacto con sus familias. Las mujeres de esta red fueron quienes me advirtieron sobre el papel de las abuelas en el contexto de la migración ecuatoriana a España. Estos contactos también me relacionaron con personas en la ciudad de Santo Domingo de los Colorados, lugar donde pude observar, principalmente, la problemática de los/as adolescentes de familias migrantes.

\section{Entre «llapingachos», «cebollas encurtidas», «ceviches», «fanesca», «sancochos» $\mathbf{y}$ «chompas» ${ }^{13}$ a medio terminar: cocinando y tejiendo historias}

Nuestra convivencia con varios grupos domésticos involucrados en nuestra investigación, mi condición de inmigrante en España y mis relaciones de amistad con las personas residentes en Murcia, Barcelona y Madrid me permitieron construir un entorno favorable para plantear las modalidades de las entrevistas. Por las tardes cuando ya había concluido mi observación participante en algunos lugares específicos y mis entrevistas con profesionales, mientras preparábamos la cena e íbamos hilando historias, eran los momentos oportunos para colocar la grabadora. A partir de algunas preguntas realizadas por mí, las mujeres hacían referencia a historias que recordaban sobre sus vecinos y vecinas y establecían significativos puntos de comparación entre las historias y trayectorias migratorias de sus propias familias y de sus amigos o vecinos.

Con respecto a los niños y niñas las entrevistas no fueron grabadas, salvo en las ocasiones que ellos y ellas lo requerían porque querían hacerlo «igual que los grandes». El ambiente para trabajar con niños y niñas se creaba en torno a juegos

${ }^{13}$ Llapingachos, cebollas encurtidas, ceviches, fanesca y sancochos son comidas típicas de la Sierra y la Costa ecuatoriana que requieren de una minuciosa elaboración y largas horas dentro de la cocina. Las chompas son jerseys, pulloveres. 
y nuestro gusto compartido por el fútbol y la música; en estos casos, debía ser extremadamente cuidadosa debido a que el tema de la migración de sus padres era muy conflictivo y difícil de entender por ellos/as. En este sentido, mi «entrada al campo infantil» sólo la realizaba cuando ellos me preguntaban si era amiga de sus madres, si había conocido a sus padres o si ellos me podían dar alguna carta para que yo la trajera a España.

La «entrada a los conflictos familiares» se vio favorecida, preferentemente, por las mujeres, mi condición de mujer migrante en España me permitía entablar largas conversaciones sobre los temas familiares a uno y otro lado del océano, entre tejidos y recetas de cocina intentábamos desenredar los nudos de la «madeja migratoria».

\section{Entrar en las cadenas y redes migratorias: mi espacio intermediario}

Una dimensión especial adquiría afrontar una investigación con una problemática donde se privilegian situaciones ligadas al conflicto y tensiones dentro de un tipo de organización social; en nuestro caso específico, el reconocimiento de la existencia de las relaciones de poder dentro de la familia, entre amigos y vecinos implicaba algunas dificultades metodológicas. Una condición fundamental fue alcanzar un nivel de confianza con la población con la cual iba a trabajar para poder registrar lecturas diferentes sobre la realidad social, distintas valoraciones sobre situaciones ligadas a la experiencia migratoria y a la heterogeneidad de intereses en disputa que pudieran generar tensiones y conflictos tanto al interior del grupo doméstico como dentro de las redes.

Existen un sinnúmero de situaciones que, por lo general, los y las migrantes suelen esconder ante el o la investigadora de campo y la información recabada en este tipo de estudios depende, en gran medida, en la confianza mutua, una variable psicosocial compleja. Como sostiene Larissa Lomnitz (1994), la confianza describe una situación entre dos individuos que implica un deseo y una disposición mutua para iniciar y mantener una relación de intercambio recíproco. Por lo tanto, la confianza presupone un cierto grado de familiaridad (proximidad social) que en mi caso estuvo dado por ser inmigrante latinoamericana, un acercamiento (proximidad física) que generé de diferentes formas en las tres áreas de estudio y por ciertas condiciones de carencias compartidas (compatibilidad de carencias, proximidad económica), desde el lugar de origen y en el lugar de llegada. De hecho, la precariedad económica del inmigrante se ve agravada por los obstáculos jurídicos. Ello hacía que, por ejemplo, mi «tarjeta de estudiante» tuviera aún un estatus jurídico más bajo que sus permisos de residencia y trabajo. Cabe destacar que la relación con inmigrantes ecuatorianos que provenían del ámbito educativo nos permitió intercambiar puntos de vista comunes en relación a los problemas sociopolíticos en nuestros países; además como la mayoría de ellos eran profesionales comprendían el alcance de los objetivos de mi trabajo y el hecho que su desarrollo estuviese vinculado a mi sobrevivencia en España. 
Mi condición de migrante latinoamericana hacía que fuera más fácil abordar con la población inmigrante los temas sobre discriminación en España y qué pensaba la población ecuatoriana de los españoles. En síntesis, la condición de extranjero/a establecía una relación de distancia con la sociedad de llegada, de este modo, me construyeron como «otra» pero con una mayor cercanía a ellos debido a las condiciones socioeconómicas, políticas y culturales que compartíamos.

Por ello, viajar al Ecuador y convivir con los miembros del grupo doméstico que se hacían cargo del proyecto migratorio en origen junto al nivel de confianza adquirido en destino me permitió comprender algunos conflictos y tensiones internas de las familias migrantes que traspasaban los problemas económicos y que descorría el velo sobre una serie de elementos simbólicos que marcaban todo el proceso migratorio.

\section{Unos de mis espacios intermediarios: vivenciar el transnacionalismo como inmigrante y latinoamericana}

Luego de haber adquirido el voto de confianza y afianzar mi posición entre los vínculos sociales entre las cadenas y redes migratorias con las cuales trabajaba, fue sencillo organizar mi trabajo de campo en el Ecuador. La primera «entrada a un campo social transnacional» se ponía de manifiesto en la confianza que depositaron en mí algunos líderes para llevar importantes sumas de dinero a sus familiares, incluso mercaderías que formaban parte de sus negocios transnacionales. Este hecho iba aunado a que ellos/as mismos/as habían organizado mi estadía en sus hogares comunicándose desde España con sus padres, madres, hermanos y hermanas.

En los lugares de origen, debido a todos los datos recogidos de cada una de las familias, las entrevistas se hicieron totalmente flexibles y se siguió los deroteros que llevaba la conversación. Esta flexibilidad me permitió moverme con mayor soltura. Además, mi conocimiento previo del Ecuador y mis vivencias allí, generaba mayor fiabilidad a algunas de mis observaciones y menor desconfianza a mis preguntas «más comprometedoras» en cuanto a los «arreglos familiares».

Estas ventajas, a menudo, complejizaban mis espacios intermediarios. En efecto, debido a la información que manejaba entre las relaciones familiares transnacionales, se me consultaba y se me pedía que tomara posición sobre algún conflicto familiar. De todas maneras, en algunos casos, estos complejos desplazamientos como investigadora, inmigrante latinoamericana y amiga de algunos/as inmigrantes fueron claves y determinantes en la construcción de una relación de igualdad y de cooperación entre los sujetos conocidos y el sujeto cognoscente, relación que permeó todo el proceso de investigación. 


\section{El estudio longitudinal de los procesos migratorios}

Desde el año 2003 hasta la actualidad, mi investigación se ha centrado específicamente en los cambios en las prácticas de crianza en las familias ecuatorianas y las renegociaciones de las relaciones de género y generacionales en este nuevo contexto migratorio trasnacional y de qué manera tanto los contextos educativos en Ecuador y en Cataluña enfrentan los desafíos que supone la presencia del hecho migratorio dentro de las aulas (Pedone 2006b; 2006c). En este contexto, además de incorporar nuevas familias migrantes a la investigación, he continuado con entrevistas periódicas a miembros de familias migrantes ecuatorianas que se revelaron, en un principio, como líderes de las redes migratorias, para conocer las resignificaciones del proyecto migratorio, cambios de estrategias, modalidades de reagrupación familiar y relecturas de las ideas de asentamiento definitivo y del retorno atravesadas por las relaciones de género y generacionales ${ }^{14}$.

El estudio de caso que presento a continuación es el resultado de este contacto periódico con las familias procedentes de El Pindal (Loja) desde hace una década. Mi trabajo con los y las migrantes que han conformado esta cadena y red migratoria en Barcelona, Montblanc (Cataluña) y El Pindal en el Ecuador me ha permitido analizar sus trayectorias laborales, los laberintos burocráticos seguidos para obtener la regularidad jurídica y las resignificaciones del proyecto migratorio que abarcan desde la reagrupación familiar en destino hasta el retorno selectivo de algunos de los miembros de las cadenas migratorias.

Es oportuno destacar que siguiendo la postura metodológica descrita, dos líderes migrantes procedentes de El Pindal, con los cuales trabajo desde hace una década, se han implicado activamente para actualizar el estado de los vínculos y la configuración de esta red migratoria, por lo cual, hemos realizado el trabajo de campo juntos a lugares como Montblanc para analizar la dinámica de la diversificación de las cadenas migratorias familiares y el mantenimiento de las relaciones a través de la red.

\section{DINÁMICA Y ARTICULACIÓN DE UNA CADENA Y RED MIGRATORIA ENTRE 1994-2009: DESDE EL PINDAL A CATALUÑA Y DESDE CATALUÑA A EL PINDAL}

A partir de 1999, la agudización de la crisis socioeconómica ecuatoriana junto a una mayor demanda de mano de obra femenina en las ciudades grandes de

${ }^{14}$ Para profundizar en el análisis de los cambios en las modalidades de los procesos de reagrupación familiar de la migración ecuatoriana hacia España reconstruidos a partir de un análisis diacrónico como el aquí propuesto, consultar: Pedone, Claudia (2008), «D’Equador a Catalunya: la gestió de la vida quotidiana de les famílies migrants». Barcelona societat. Revista de coneixement $i$ análisis social. N. ${ }^{\circ} 15$, p. 81-87. 
España ha provocado que la mujer se convierta en el primer eslabón de la cadena migratoria. La participación determinante de la mujer en el desplazamiento de la población ecuatoriana hacia Europa y, específicamente, hacia España ha generado un reacomodamiento en las relaciones de género y entre las generaciones. Por ello, la visibilización de las mujeres y de los niños dentro del grupo doméstico y como parte decisional en el juego de las relaciones de poder ha permitido centrar el análisis de la familia como un lugar de conflicto y negociación y analizar sus transformaciones dentro de un contexto migratorio transnacional.

La conformación de las cadenas migratorias respondían al fenómeno de la feminización del flujo migratorio ecuatoriano, es decir, las mujeres que pertenecen a esta red migratoria, en su mayoría, son los primeros eslabones de las cadenas migratorias familiares y han propiciado la reagrupación en destino de los varones del grupo doméstico y de sus hijos e hijas. Una buena parte de las personas procedentes de El Pindal (provincia de Loja) eran profesionales de la educación y tenían un prestigio social en su localidad de origen, que posteriormente contribuiría a consolidar líderes migrantes con «autoridad moral».

En cuanto a la «entrada al campo» en Loja y El Pindal, dos cadenas migratorias residentes en Barcelona me posibilitaron el contacto con sus familias. Las mujeres de esta red fueron quienes, en un grupo de discusión en Barcelona, debatieron sobre el papel de las abuelas en el contexto de la migración ecuatoriana a España y la necesidad de investigar en origen qué estaba pasando en ciudades pequeñas y pueblos donde abuelas, abuelos, niños, niñas y adolescentes formaban nuevas redes de cuidados, nuevas estructuras familiares a partir de la migración de los adultos.

Cabe destacar que existen cadenas migratorias acotadas a grupos domésticos nucleares y consolidados que han mantenido una horizontalidad en sus relaciones a lo largo de los años, este marcado rasgo de solidaridad y cooperación con connacionales puede deberse a que sus primeros vínculos «débiles» los establecieron con personas autóctonas y ONGs que les proporcionaron las claves para entrar en los circuitos laborales y de vivienda; además, son ejemplos de cadenas migratorias que no han utilizado la información de la que disponen como una práctica económica.

Virginia y Darío comenzaron su trayectoria socioespacial en Bélgica a principios de la década de 1990, luego trabajaron en Madrid hasta establecerse definitivamente en Barcelona, después de haber intentado, en 1999, un retorno frustrado a Loja. Su relación con el lugar de origen está basada en una densa trama de vínculos «fuertes», luego de ver frustrados los planes de retorno debido a la crisis económica del Ecuador, decidieron establecerse en Barcelona pero sin perder el contacto fluido y continuo con origen. A partir de la reagrupación en destino su principal objetivo se orientaba a que sus hijos disfrutaran de los servicios sociales que el estado de bienestar europeo ofrecía, específicamente la educación, sus estrategias están circunscritas a la cadena familiar, y el fruto de su trabajo lo invierten tanto en destino como en origen, dentro de un grupo doméstico nuclear. Actualmente, sus dos hijos mayores han retornado a trabajar y 


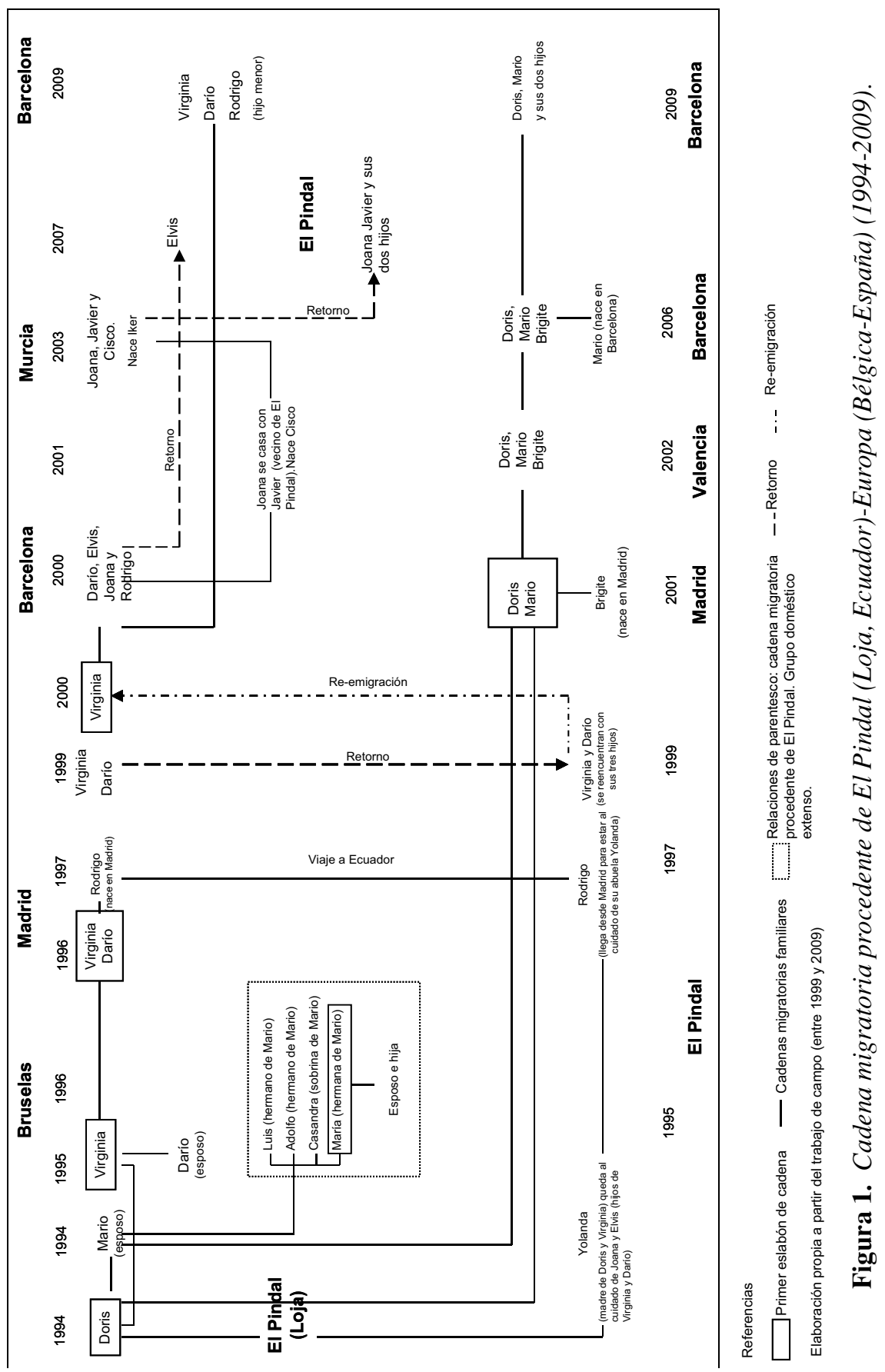

EMPIRIA. Revista de Metodología de Ciencias Sociales. N. . 19, enero-junio, 2010, pp. 101-132. ISSN: 1139-5737 
continuar sus trayectorias universitarias en Loja (Ecuador) y tanto Virginia como Darío se han convertido nuevamente en madre y padre transnacionales que deben reanudar sus envíos de remesas a origen para sostener económicamente estos retornos ${ }^{15}$.

Como matrimonio sus trayectorias espaciales y sociales, desde un inicio los vincularon más con actores autóctonos, lo cual les permitió entrar a una red de acceso al trabajo más diversificada debido a los contactos que poseían en Europa. Su relación con otros inmigrantes ecuatorianos se circunscribe a relaciones de amistad y de vecindad en un ámbito donde prevalecen las relaciones horizontales por lo cual acceder a la información que ellos disponen en cuanto a trabajo y vivienda no posee un valor mercantil ${ }^{16}$.

No obstante, dentro de la red migratoria se constituyeron en los migrantes más antiguos y con mayor prestigio y autoridad. Tanto los pioneros como las pioneras se constituyeron en actores con cierta «autoridad» que los y las colocaba en una posición privilegiada en el inicio de la conformación de las redes migratorias entre el lugar de origen y de destino. Dentro de estos grupos domésticos existe una complejidad del vínculo que se manifiesta en la asimetría de las relaciones de género y en el prestigio que adquiere el/la emigrante de mayor antiguiedad, que ha conseguido con éxito los objetivos planteados en el proyecto migratorio. En algunos grupos es la mujer la que controla las relaciones de poder, en otros es el varón y, en otros el matrimonio es el que el que toma conjuntamente las decisiones, manejan los ahorros y los contactos con otros inmigrantes (Pedone, 2006). La manera en que se lleva a cabo este juego de poderes incide en el prestigio que esta cadena migratoria tiene en el lugar de origen, principalmente, si este lugar es un barrio o un pueblo pequeño, como ocurre con El Pindal.

\section{La diversificación de las cadenas migratorias: estrategias laborales y de vivienda}

La articulación y dinámica entre las cadenas y redes migratorias requiere de algunos matices que intentaremos abordar desde lo que anteriormente explicamos como la diversificación de las cadenas migratorias y la consolidación de las redes migratorias en campos sociales transnacionales ${ }^{17}$.

${ }^{15}$ Ver Figura N. ${ }^{\circ} 1$.

${ }^{16}$ Si bien en este artículo presentamos la articulación y configuración de una red migratoria donde prevalecen las relaciones horizontales y el ejercicio de una «autoridad moral», en otras redes estudiadas la dinámica de la red giraba en torno, preferentemente, a relaciones verticales y el ejercicio de una «autoridad económica». Al respecto consultar Pedone, C. (2006): Estrategias migratorias y poder. 'Tú siempre jalas a los tuyos', Quito, ABYA-YALA-PMCD-AECI (pp.134138).

${ }^{17}$ Ver Figura N. ${ }^{\circ} 2$.

EMPIRIA. Revista de Metodología de Ciencias Sociales. N. . 19, enero-junio, 2010, pp. 101-132.

ISSN: $1139-5737$ 
Como explicáramos en el punto II, la ampliación lugares de destino y la consolidación de los vínculos transnacionales genera la diversificación de las cadenas. Desde mediados de la década de 1990 cuando se inician las primeras trayectorias migratorias procedentes de El Pindal hacia Europa, este desplazamiento ha sido encabezado por mujeres quienes, en su mayoría, han reagrupado a los varones e hijos/as del grupo doméstico. El primer desplazamiento internacional se inicia hacia Bélgica donde las mujeres se insertan en el servicio doméstico interno y propician proyectos migratorios de otras mujeres pertenecientes a las relaciones de parentesco y vecindad. Estas mujeres pioneras cumplen con dos mandatos que ya contemplaba el diseño del proyecto migratorio: saldar la deuda y «traer al marido». Las condiciones de llegada y asentamiento de estas mujeres y varones de El Pindal en Bélgica estuvieron marcadas por una fuerte precariedad laboral, residencial y, principalmente, jurídica.

A mediados de la década de 1990, la constante persecución policial, llevó a varias mujeres a activar contactos con otros y otras connacionales que ya estaban migrando a España y así generaron un cambio en sus trayectorias migratorias. Las pioneras en Bélgica, también lo fueron en Madrid y Barcelona y paulatinamente reoganizaron las cadenas y redes migratorias en estas dos ciudades articulando estrategias en torno al acceso al trabajo y a la vivienda.

La articulación de esta red migratoria en España no coincide temporalmente con la masificación y aceleración del flujo migratorio ecuatoriano que se produce entre 1999 y 2001 . Este hecho explica que para esta época la mayoría tuviera resulta su situación jurídica y comenzaran a planificar las primeras reagrupaciones familiares.

Paralelamente, la estrecha vinculación entre los miembros de esta red migratoria ha generado una circulación fluida de información en cuanto a contactos laborales y prácticas económicas y financieras para adquirir vivienda en propiedad. Doris, Mario, Virginia y Darío fueron los primeros en salir de nichos laborales precarios, luego de una década de iniciada la migración lograron comenzar con trayectorias laborales autónomas o insertarse en empleos mejor remunerados y donde se reconocía cierta cualificación profesional.

Doris y Virginia se convirtieron en empresarias por medio de la gestión de una empresa familiar de alquiler pisos de alto standing para ejecutivos o personas de altos ingresos que llegan a Barcelona por pocos días junto al servicio de limpieza y traslados desde el aeropuerto a la ciudad. Su liderazgo dentro de la red migratoria se ha afianzado por dos razones: la primera es que siguen gestionando información de calidad en cuanto a contactos laborales y de vivienda y la segunda es que han otorgado trabajo a otros y otras inmigrantes latinoamericanas con contratos de trabajo que han permitido regularizar su situación a varias familias migrantes.

Además, la compra de pisos mediante hipotecas en Barcelona, Valencia y Murcia, donde la hija de Virginia se trasladó por el empleo de su esposo, también ha constituido un ejemplo pionero en la diversificación de las cadenas mi- 
gratorias y la movilidad espacial en los lugares de destino en relación a las estrategias residenciales.

En 2001 se inicia una nueva diversificación de cadenas migratorias hacia Montblanc (Cataluña). Esta época coincide con el período de aceleración del flujo migratorio ecuatoriano y con una situación extendida de irregularidad jurídica. Nuevamente los y las líderes de esta red otorgan a sus familiares, amigos y vecinos contactos laborales en el servicio doméstico interno, cuidado de ancianos y en la construcción, hecho que conduce a que la red migratoria también se diversifica hacia Montblanc, donde varios grupos domésticos, pasados dos o tres años, comienzan con los procesos de reagrupación familiar y la compra de vivienda mediante hipotecas, a pesar de la precariedad laboral a la cual estaban sometidos y sometidas.

\section{La gestión de la vida cotidiana en un contexto migratorio transnacional: redes de cuidado, asentamiento en destino y retornos}

A mediados de la década de 1990, las abuelas de El Pindal comenzaron a hacerse cargo de la crianza de sus nietos y nietas. En nuestra primera investigación (Pedone, 2004) ya adelantábamos el papel clave que jugaban las abuelas en la gestión y el sostenimiento en el tiempo de la red de cuidados en origen hasta el momento de la reagrupación en destino. En El Pindal estos arreglos familiares comenzaron a inicios de la década de 1990 cuando salieron las primeras mujeres a Europa. Durante estas dos últimas décadas la gestión de la vida cotidiana a nivel transnacional ha pasado por varias etapas.

En una primera etapa, las mujeres migrantes permanecieron varios años en el servicio doméstico interno, motivo por el cual no se planteaba la reagrupación en destino y mantuvieron durante varios años el ejercicio de la maternidad transnacional (Pedone, 2004; Pedone; Gil Araujo, 2008). En el caso de El Pindal, algunas mujeres ante esta precariedad laboral y residencial debieron enviar a sus hijos recién nacidos en España a Ecuador para que las abuelas aseguraran la crianza. Durante estos años el rol cumplido por las abuelas y algunas tías fue fundamental, posteriormente entre 2001 y 2003 comenzaron las reagrupaciones en destino y poco a poco El Pindal dejó de ser un pueblo de viejos y niños para pasar a ser un pueblo de mayores.

Es oportuno destacar que la red migratoria de El Pindal aunque haya afianzado proyectos laborales y residenciales en destino, en casi todas las familias entrevistadas, no se ha cortado el flujo de remesas, incluso después de las reagrupaciones. El flujo de dinero ha seguido en pos de realizar inversiones, principalmente, en la construcción de viviendas y promoción de negocios de comercio.

Los vínculos transnacionales se siguen afianzando entre origen y destino debido a que se están produciendo algunos retornos. Por un lado, comenzaron a retornar algunos hijos e hijas que querían iniciar sus trayectorias personales 


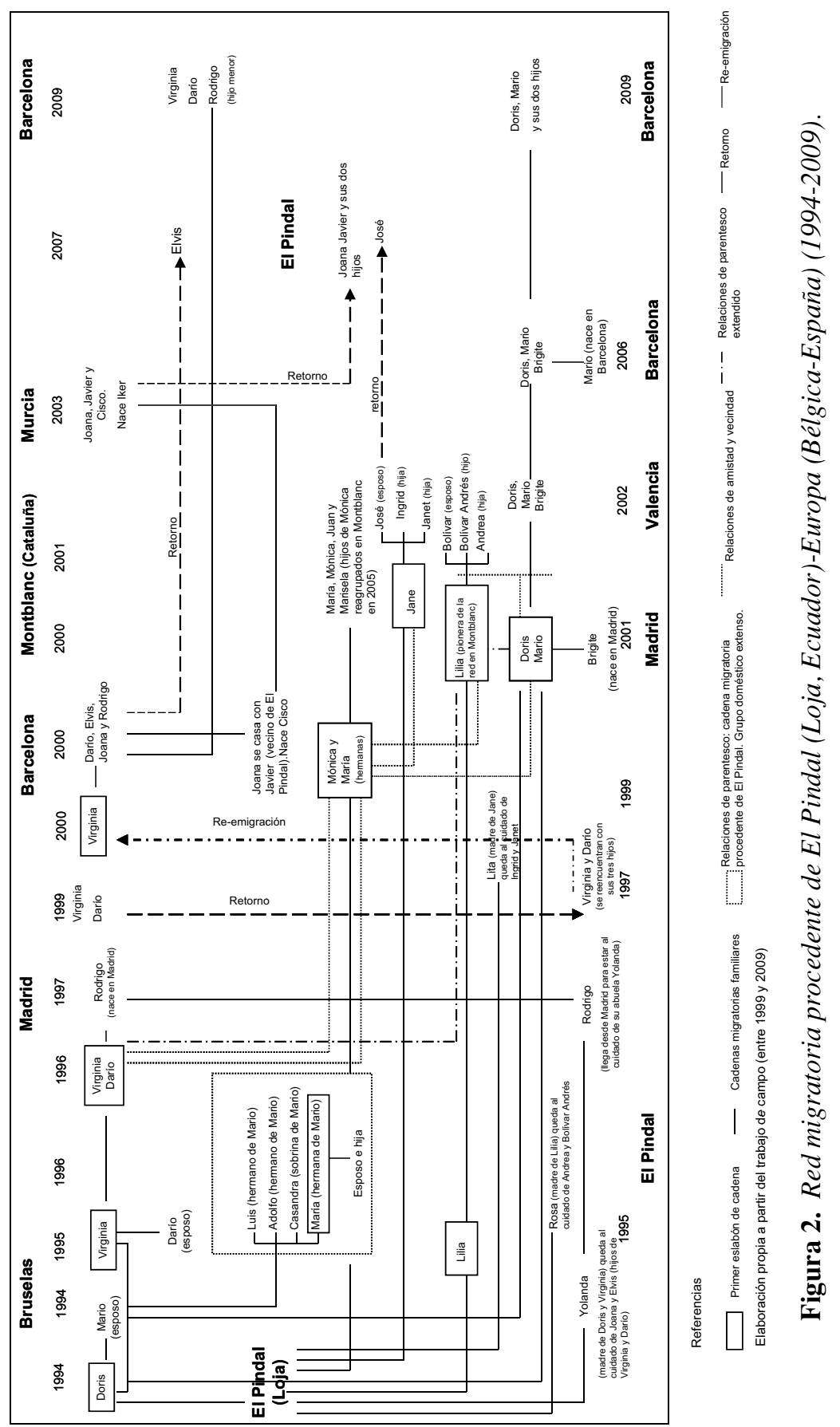

EMPIRIA. Revista de Metodología de Ciencias Sociales. N. . 19, enero-junio, 2010, pp. 101-132. ISSN: 1139-5737 
en origen y los adultos están reforzando el envío de dinero para emprendimientos comerciales o trayectorias educativas universitarias. En el último tiempo, la crisis económica en España ha conducido a algunos y algunas migrantes a plantearse el «retorno voluntario» propuesto por el Estado español, debido a que han perdido sus trabajos y han debido entregar los pisos hipotecados al banco, con la pérdida de recursos económicos y financieros que este hecho conlleva.

En el año 2000 cuando fui invitada, por primera vez, a una cena de la red migratoria de El Pindal en Barcelona, organizada por los pioneros de la migración internacional, la discusión se centraba en las estrategias laborales y jurídicas y en cómo gestionar la crianza de los hijos e hijas en origen. A partir de 2003, con la entrada del visado, los temas de discusión se centraban en las estrategias de reagrupación familiar y en los procesos de adaptación de niños, niñas y adolescentes en los ámbitos socioeducativos en destino. En marzo de 2009 , les propuse reunirnos para actualizar «nuestro gráfico de la cadena y red migratoria de El Pindal» para poder escribir este artículo. Nos reunimos en una comida en Montblanc, miembros de seis de las familias con las cuales trabajo desde los inicios de la década de 2000. El otro objetivo era entrevistar a los adolescentes reagrupados para conocer sus intereses personales a partir de la migración familiar y la reagrupación en destino ${ }^{18}$. En esta última ocasión, el tema principal de conversación era de qué manera la crisis económica española estaba impactando en sus vidas y el tema recurrente era el retorno. En resumen, si hace una década se debatía entre las familias quién era el miembro del grupo doméstico que reunía las mejores condiciones para migrar, actualmente, se reflexiona acerca de cuál es la mejor estrategia para combinar el retorno de algunos de sus miembros y la permanencia de otros y otras en destino para seguir generando recursos económicos. Contrariamente a lo postulado por algunos discursos políticos, amplificados por los medios de comunicación, sobre el retorno masivo de migrantes; nuestro trabajo de campo demuestra que el retorno será selectivo y organizado sobre la base de nuevas estrategias migratorias que se están diseñando y poniendo en práctica.

\section{CONCLUSIONES}

Enfocar el estudio de las estrategias migratorias de la población ecuatoriana desde la articulación y la dinámica de cadenas específicas, en primera instancia, me permitió ahondar en la explicación de un proceso colectivo, en el cual las decisiones sobre el proyecto migratorio involucran a varias generaciones del grupo doméstico y sus relaciones de poder. Mientras que extender la perspectiva de

18 Actualmente, llevo a cabo el estudio. «Los hijos e hijas de la migración ecuatoriana a Cataluña: rupturas y continuidades en los roles de género», investigación por encargo de la Fundació Jaume Bofill (en curso).

EMPIRIA. Revista de Metodología de Ciencias Sociales. N. o 19, enero-junio, 2010, pp. 101-132. ISSN: $1139-5737$ 
análisis hacia estructuras mayores como las redes migratorias nos posibilitó comprender los vínculos generados entre amigos, vecinos y otros actores que intervienen en los procesos migratorios actuales hacia España y su posterior inserción socioeconómica en destino.

La construcción de esta propuesta teórico-metodológica considera a los y las migrantes y grupos capaces de realizar ciertas elecciones, de diseñar estrategias de supervivencia y de movilidad geográfica y social. Este enfoque constituyó una buena herramienta teórico-metodológica para analizar algunos aspectos que resumimos a continuación:

- Considerar un mayor número de variables: demográficas, económicas, sociales, políticas y culturales.

- Recuperar una aproximación microhistórica que supuso desafíos metodológicos: un estudio longitudinal basado en un trabajo de campo etnográfico transnacional (origen y destino) que derivó en una reflexión metodológica sobre las políticas de trabajo de campo.

- Superar las nociones bipolares (origen y destino) y sustituirlas por una concepción multilocal y circular en la cual se producen intercambios mucho más complejos entre los distintos lugares de origen y múltiples lugares de destino.

- Analizar los reacomodamientos en las relaciones de género y generacionales en un contexto migratorio transnacional.

- Superar la visión retórica e idílica del uso de las cadenas y redes migratorias sobre la cohesión y la solidaridad. Además, mantener un nivel de análisis diferenciado entre cadena y red migratoria enriqueció el estudio de los procesos migratorios desde la perspectiva de los vínculos horizontales y verticales y demostró que los mismos no son excluyentes dentro de estas estructuras sociales.

- Identificar la reactivación de cadenas migratorias ante coyunturas socioeconómicas y políticas desfavorables en origen y así superar la mirada reduccionista que caracterizaría a los flujos migratorios como homogéneos, e indiferenciados.

- Introducir la variable de género como un principio organizador de los flujos migratorios.

- Diferenciar y analizar prácticas sociales, económicas y financieras del comportamiento mafioso que, en numerosas ocasiones, se les ha atribuido a las redes.

- Complementar este abordaje con una perspectiva transnacional y transatlántica me ha permitido analizar en el transcurso de una década las trayectorias socioespaciales de varones y mujeres ecuatorianas desde el diseño de su proyecto migratorio, pasando por las resignificaciones del mismo, todas decisiones y estrategias atravesadas por las relaciones de género y generacionales, específicamente, a partir de la salida de la mujer como primer eslabón de la cadena migratoria. 
- La investigación continuada de los últimos años confirma de qué manera los y las migrantes han demostrado su capacidad para elaborar estrategias migratorias, laborales, residenciales, jurídicas, políticas y familiares que les permitan sortear los obstáculos, controles y restricciones que interponen los países de destino al movimiento internacional de trabajadores y trabajadoras pobres en este nuevo orden hegemónico mundial. Estrategias migratorias que afianzan y consolidan los procesos de transnacionalismo, en el afán de las familias migrantes de gestionar la vida cotidiana de sus miembros y asegurar la supervivencia en contextos socioeconómicos y políticos cada vez más excluyentes.

\section{BIBLIOGRAFÍA}

BAILY, S. (1988): «Cadenas migratorias de italianos a la Argentina: algunos comentarios», Estudios Migratorios Latinoamericanos, 8, pp. 125-135.

BorRIE, W. (1954): Italians and Germans in Australia, Melbourne, Melbourne University Press.

Bragoni, B. (1999): Los hijos de la revolución. Familia, negocios y poder en Mendoza en el siglo XIX, Buenos Aires, Taurus.

Bustos CoRTÉs, A. (1993): «Investigaciones sobre inmigración en España», Sociedad y Utopía. Revista de Ciencias Sociales, 1, pp. 151-158.

Clyde Mitchell, J. (1969) (ed.): Social Networks in Urban Situations. Analyses of Personal Relationships in central African Towns, Manchester, Manchester University Press.

Colectivo IoÉ (1999): Inmigrantes, trabajadores, ciudadanos, Valencia, Patronat SudNord-Universitat de Valencia.

De Oliveira Assis, G. y Siqueira, J. (2009): «Mulheres emigrantes e a configuraçao de redes sociais:construindo conexões entre o Brasil e os Estados Unidos», REMHU, 32, pp. 25-46.

Devoto, F. (1988): «Las cadenas migratorias de los italianos a la Argentina: algunos comentarios», Estudios Migratorios Latinoamericanos, 3, 18, pp. 125-134.

- (1991), «Algo más, sobre las cadenas migratorias de los italianos a la Argentina». Estudios Migratorios Latinoamericanos, 6, 9, 323-343.

FANZITO, D. (2009): «The role of social Networks in human migration», REMHU, 32, pp. $5-24$

GARCÍA BORREGO, I. (2000): «Acerca de la teoría y la práctica de la investigación sobre inmigración en España», II Congreso sobre la inmigración en España, Madrid, CD.Rom

GarCía CANClini, N. (1990): «Introducción: la sociología de la cultura de Pierre Bourdieu», en Sociología y cultura, México, Grijalbo, pp. 7-20.

Glick Schiller, N. (1995): «From Inmigrant to Transmigrant: Theorizing Transnational Migration», Anthropology Quartely, 68 (1), pp. 48-63.

GoLBY, J. (1997): «Autobiographies, Letters and Diaries», en Studying Family and Community History $19^{\text {th }}$ and $20^{\text {th }}$ Centuries. Sources and Methods: A Handbook, Cambridge, Cambridge University Press/ The Open University.

GranovetTer, M. (1974): Getting a Job, Cambridge, Harvard University Press; 2. ${ }^{a}$ ed. Chicago, University of Chicago Press, 1994. 
Gregorio GIL, C. (1998): Migración femenina. Su impacto en las relaciones de género, Madrid, NARCEA S.A. Ediciones.

GRIBAUDI, M. (1987): Mondo operaio e mito operaio:spazi e percorsi sociali a Torino nel primo Novecento, Torino, Enaudi.

GrIECO, M. (1987): Keeping it in the Family. Social networks and employment chance. London and New York: Lavistock.

GURAK, D. Y CACES. F. (1998): «Redes migratorias y la formación de sistemas de migración», en Cruzando fronteras. Migraciones en el sistema mundial, Barcelona, Icaria-Fundación Hogar del empleado, pp. 75-112

HARNEY, R. (1984): Dalla frontiera alle Litlle Italies, Roma.

HorkHEIMER, M. (1980): Teoría crítica, Buenos Aires, Amorrortu editores.

- (1986): «La familia y el autoritarismo», en La familia, Barcelona, Península, pp. 177194.

KATZ, C. (1992): «All the world is staged: intellectuals and the projets of ethnography», Environment and Planning D: Society and Espace, 10, pp. 495-510.

- (1994): «Jugando en el campo. Cuestiones referidas al trabajo de campo en Geografía», The Professional Geographer, 46, 1, pp. 67-72.

LEVI, G. (1993), «Antropología y microhistoria: conversación con Giovanni Levi». Manuscrits, 11, 15-28.

LeVITT, P. y Glick SchILleR, N. (2004): «Perspectivas internacionales sobre migración: conceptuar la simultaneidad», Migración y Desarrollo, Segundo Semestre, 3 , pp. 60-91.

LEWIS, O. (1972): La cultura de la pobreza, Barcelona, Anagrama.

LochORE, (1951): From Europe to New Zeland, New Zeland, Wellington Press.

LoMNITZ, L. (1975): ¿Como sobreviven los marginados?, México, Siglo XXI editores.

- (1994): «Redes informales de intercambio en sistemas formales: un modelo teórico», en Redes sociales, cultura y poder: ensayos de antropología latinoamericana, México, FLACSO, pp. 135-166.

Macdonald, J. Y Macdonald, L. (1964): «Chain Migration, Ethnic Neighbourhood Formation and Social Networks», The Milbank Memorial Fund Quartely, 1, pp. 82-96.

MAHLER, S. y PeSSAR, P. (2006): «Gender Matters: Ethnographers Bring Gender From the Perifery Howard the Core of Migration Studies», International Migration Review, 1, pp. 27-63.

Malgesini, G. (1998): «Introducción», en Cruzando fronteras. Migraciones en el sistema mundial. Barcelona: Icaria.Fundación Hogar del empleado, pp. 11-42.

- y Giménez, C. (1997): Guía de conceptos sobre migraciones, racismo e interculturalidad, Madrid, La Cueva del Oso.

Massey, Douglas. y EsPINOSA, K. (1999): «Undocumented Migration and the Quantity and Quality of Social Capital», en Migration and Trasnational Social Spaces, Sidney, Ashsgate, pp. 106-137.

Miguez, E. (1995): «Microhistoria, redes sociales e historia de las migraciones: ideas sugestivas y fuentes parcas», en Inmigración y redes sociales en la Argentina Moderna, Buenos Aires, CEMLA-IEHS, pp. 23-34.

- (1995): «Microhistoria, redes sociales e historia de las migraciones: ideas sugestivas y fuentes parcas», en Inmigración y redes sociales en la Argentina Moderna, Buenos Aires, CEMLA-IEHS, pp. 23-34.

MolinA, J.L. (2001): Las redes sociales. Una introducción, Barcelona, Edicions Bellaterra. 
MoroKvasic, M. (1984): «Bird of Passage are also Women», International Migration Review, 4, pp. 886-907.

Pedone, C. (2008): «D’Equador a Catalunya: la gestió de la vida quotidiana de les famílies migrants». Barcelona societat. Revista de coneixement $i$ análisis social. $\mathrm{N}$. $15, \mathrm{p} .81-87$.

Pedone C. y Gil Araujo, S. (2008): «Maternidades transnacionales entre América Latina y el Estado español. El impacto de las políticas migratorias en las estrategias de reagrupación familiar», en Nuevos retos del transnacionalismo en el estudio de las migraciones, Madrid, OPI-Ministerio de Trabajo e Inmigración, pp. 149-176.

PEDONE, C. (2006a): Estrategias migratorias y poder. Tú siempre jalas a los tuyos, Quito, ABYA-YALA, PCMD.

- (2006b): De l'Equador a Catalunya: El paper de la familia i les xarxes migratòries, Barcelona, Editorial Mediterrània.

- (2006c): «Los cambios familiares y educativos en los actuales contextos migratorios ecuatorianos: una perspectiva transatlántica», Athenea Digital, 10, pp. 154-17.

- (2005): "'TÚ SIEMPRE JALAS A LOS TUYOS'. Cadenas y redes migratorias de las familias ecuatorianas hacia España», en La migración ecuatoriana. Transnacionalismo, redes e identidades, Quito, FLACSO-PMCD, pp. 105-146.

- (2004): «'Tú siempre jalas a los tuyos'. Cadenas y redes migratorias de las familias ecuatorianas hacia España», Tesis Doctoral, Barcelona, Universitat Autònoma de Barcelona (inédita).

- (2002): «El potencial del análisis de las cadenas y redes migratorias en las migraciones internacionales contemporáneas», en Actas del III Congreso sobre la inmigración en España. Contextos y alternativas, Granada: Laboratorio de Estudios Interculturales, Vol.II, pp. 223-235.

- (2000): «El trabajo de campo y los métodos cualitativos. Necesidad de nuevas reflexiones desde las geografías latinoamericanas», Scripta Nova. Revista Electrónica de Geografía y Ciencias Sociales, 57, (en línea) http://www.ub.es/geocrit/sn-57.htm. [Consulta 1 de febrero de 2000].

Pessar, P. (1984): «The linkage between the Household and Workplace of Dominican Women in the U.S.», International Migration Review, 4, pp. 1188-1210.

PISElli, F. (1995) (comp.): L'analisi di network nelle scienze sociali, Roma, Donzelli Editore.

PORTES, A. Y BÖRÖCZ, J. (1998): «Migración contemporánea. Perspectivas teóricas sobre sus determinantes y sus modalidades de incorporación», en Cruzando fronteras. Migraciones en el sistema mundial, Barcelona, Icaria-Fundación Hogar del empleado, pp. 43-73.

PRICE, C. (1963): Southern Europeans in Australia, Melbourne, Melbourne University Press.

Pries, L. (1999): Migration and Trasnational Social Spaces, Sidney, Ashsgate.

RAMELLA (1995): «Por un uso fuerte del concepto red en los estudios migratorios», en Inmigración y redes sociales en la Argentina Moderna, Buenos Aires, CEMLA-IEHS, pp. 9-21.

Ruiz Olabuénaga, J.I. (1999), Metodología de la investigación cualitativa. Bilbao: Universidad de Deusto. 2. ${ }^{\text {a }}$ edición.

SALles, V. (1991): «Cuando hablamos de familia ¿de qué familia estamos hablando?», Nueva Antropología, 39, pp. 53-87. 
Salles, V. y Smith, M. (1987): «La reproducción según Bourdieu y Passeron, sus conceptos», Perfiles Educativos, 37, pp. 28-36.

Solana, M., Morén, R., De Miguel, V. y Pascual de Sans, A. (2002): «Migraciones en Cataluña (1975-2000). Reflexiones sobre el estado de la cuestión desde las ciencias sociales», Migraciones, 11, pp. 141-172.

STURINO, F. (1988): «Emigración italiana: reconsideración de los eslabones de la cadena migratoria», Estudios Migratorios Latinoamericanos, 8, pp. 5-25.

SuÁREZ NAVAS, L. (2008): «Lo transnacional y su aplicación a los estudios migratorios. Algunas consideraciones epistemológicas», en Retos epistemológicos de las migraciones transnacionales, Barcelona, ANTROPHOS, pp. 48-63.

TRUONG, T. (1996): «Gender, International Migration and Social Reproduction: Implications for Theory, Policy, Research and Networking», Asian and Pacific Migration Journal, 1, pp. 27-52.

VASILACHIS De GIALDINO, I. (2000): «Del sujeto cognoscente al sujeto conocido: una propuesta epistemológica y metodológica para el estudio de los pobres y de la pobreza», en Pobres, pobreza y exclusión social, Buenos Aires, CEIL-CONICET, pp. 217-246.

Weber, M. (1944): Economía y Sociedad, México, Fondo de Cultura Económica.

WIMMER, A. Y GLICK SCHILlER, N. (2002): «Methodological nationalism and beyond: nation-state building, migration and social sciences», Global Networks, 2, 4, pp. 301334.

\section{RESUMEN}

La finalidad de este artículo es presentar una propuesta teórica-metodológica que demuestre el potencial del enfoque de análisis de las cadenas y redes migratorias para analizar las trayectorias socioespaciales de las familias migrantes en los flujos migratorios contemporáneos. En primer lugar, defino conceptualmente qué entiendo por cadena y red migratoria en nuestro estudio; en segundo lugar, detallo las estrategias metodológicas que utilicé para la reconstrucción de las mismas y en tercer lugar, presento un estudio de caso sobre una cadena y red migratoria procedente de la provincia de Loja (sur de Ecuador) en sus trayectorias hacia Europa y en la construcción y consolidación de sus procesos de transnacionalismo. El análisis se centra en la dinámica y la configuración de las cadenas y redes migratorias a partir de los vínculos familiares, de parentesco y vecindad y la diversidad de trayectorias migratorias atravesadas por las relaciones de género y generacionales.

\section{PALABRAS CLAVE}

Cadenas y redes migratorias, metodología cualitativa, trayectorias migratorias, relaciones de género y generacionales. 


\begin{abstract}
The purpose of this article is to present a theoretical-methodological proposal that show the potential of the focus of analysis of the migratory chains and networks to analyze the sociospacial trajectories of the migrant families in the contemporary migratory flows. In the first place, I define conceptually what do I understand for migratory chain and network in our study; in second place, I detail the methodological strategies that utilized for the reconstruction of the same and in third place, I present a case study on a migratory chain and network originating in the province of Loja (South of Equator) in its trajectories toward Europe and in the construction and consolidation of its transnacionalism processes. The analysis itself center in the dynamics and the configuration of the migratory chains and networks from the family links, of relationship and neighbourhood and the diversity of migratory paths crossed by the relations of gender and generation.
\end{abstract}

\title{
KEY WORDS
}

Migratory chain, networks, qualitative methodology, migratory paths, relations of gender and generation. 